\section{NATIONAL, ASSOCIATION OF MILITARY SURGEONS OF THE NATIONAL GUARD OF THE UNITED STATES.}

CONCERNING THE ORGANIZATION OF THE MED ICAL DEPARTMENT OF THE NATIONAI, GUARD.

Read at the First Meeting of Nationat Guard Surgeons, at Chicago, Sept. 18,1891

BY J. D. BRIANT, M.D.,

SURGEON-GENERAL OF THE NEW YORK STATE NATIONAL GUARD.

While the title of this paper is sufficiently expressive, as it seems to me, to make its importance obvious to all concerned, still, it is not the intention of the writer now to do more than to speak of the medical officers of the Guard and their immediate aids. The scope of a complete organization for the duties of active service, as in the case of the regular army, is too extended to be considered at large at this time, and in fact it may be best considered by a careful study of the methods employed in the regular army itself. shall deem it sufficient at present to dwell upon the necessity of what may be called self evident requirements of the medical service, requirements, the advisability of which are so obvious as to hardly need more than the mention to carry conviction to all minds. Those of you who are at the head of a well organized medical department can appreciate its importance to the service, as well as the assiduity necessary for its establishment. Those who are anticipating such a desideratum can but welcome the opportunity here offered to profit alike by the facts to be presented and the friendly criticism they will necessarily inspire. I shall speak of the Guard as an entirety, giving to it the comprehensive significance of the expression National itself. This course is proper, since the prime object of the organization is similar in all States-the protection of individual and public rights from organized and otherwise ungovernable violence. And, too, in each State, the Guard is sustained by the patriotism and local pride of the citizens of communities, who as willingly perform military duty in the Guard as they pay taxes for its support. It follows from these indubitable facts that the people of these communities, and of States even, expect, as they have the right to, a wise preparation for an efficient protection from violence of private and public interests, whenever the occasion demands it. And it is equally logical to say that their approbation and support of the Guard will be directly proportionate to the actual and prospective benefits which they contemplate or receive by reason of its existence. It, therefore, follows that the medical, like every other department of the Guard, should be so organized as to give to the greatest number the greatest good at all times that is consistent with military efficiency. The necessity for such provisions in the medical department of many States is pregnant with the sentiment that teaches that:

$$
\begin{aligned}
& \text { The woes of the defenders } \\
& \text { Of a country's cause } \\
& \text { Should be soothed by a wise adjustment } \\
& \text { Of a country's laws. }
\end{aligned}
$$

This sentiment refers not alone to the sense of grateful patriotism that contemplates a liberal and substantial recognition on the part of a country of those who have served in her defense, but also it implies a practical adjustment of matters by wise measures in times of peace, for the prevention and alleviation of physical disaster in times of strife. In the amplification of this idea I cannot help but believe that the medical department of the National Guard should be so constituted that it may extend "prompt aid" to the citizen-soldier and citizen-taxpayer at all times in case of physical emergencies. The consummation of this plan can but meet the hearty approval of those it is intended to aid, and will thus cause, on their part at least, a proportionate increase in the moral and financial support of the Guard. It has been my great honor, as well as pleasure, to have been connected officially with the Guard of New York since June, 1873. About ten years of this time were devoted to regimental service, a service that enabled me to study the needs of the medical department at large, and especially to note the deficiencies of the one under my immediate charge. During the remainder and later portion of the service about nine years-I have, as surgeon-general of the State, been able, with the concurrence of the commander-in-chief, and the advice and individual support of the officers of the medical staff, to advance the status of efficiency of the medical department to a considerably higher plane than it formerly occupied. At the time of my entrance to the Guard, no properly authorized medical scrutiny of the professional qualifications of an applicant for the position of medical officer in the Guard had been establisbed, except that he shall have graduated from a medical college; and this requirement was assumed to have been complied with quite as often as it was demonstrated to have been by the exhibition of fitting credentials. And, too, at this time it was necessary that the commandant of the organization be convinced that the applicant was a "good fellow," and would "fill the bill," at least in all respects essential to good-fellowship. Good policy and good principle often parted company at this phase of requirement. At all events, the essential qualifications that constitute a proper medical officer, in the professional sense, could be made subservient to the social, financial and political considerations of the laity sense. As the result of this policy, while many good and true men were recruited, yet many-indeed, too 
many, in fact - were accepted who valued the commission only for the selfish gain they hoped for, rather than the honorable and useful record it might have in store for them. It is plain to be seen that a policy of this kind furnished not only indifferent medical service of the legally authorized type, but also opened the way for even a great abuse - the acceptance of those who were possessed of no legal qualifications whatever to practice medicine or surgery. Please do not misunderstand me; for while this abuse was of rare occurrence indeed, still the system was such that it need not have been the exception, in so far as official medical scrutiny exercised any control. It is not strange if, at this time, commanding officers often looked on their medical subordinates in the light of physical ornaments and conveniences, or as animated luxuries, to whom they might refer matters of a medical tenor for decision, when they felt condescendingly inclined, or when good policy dictated that their own opinion should have the genuine or implied approval of a medical officer. I will not dwell longer on the unfortunate realities nor the grave possibilities of this former course of action than to add that it was not the restult of indifference or dishonesty, but simply a phase in the developmental history of the Guard. Please remember that this period is twenty years to the rear of the one of to-day, and although a continuous improvement was made in this respect by the cleansing influence of a ferment of earnest and wise purposes, and the survival of the fittest, still it was not till the issuance of an order, of which the following extracts are the greater portions, that the matter was placed on an official and enduring basis :

General Headquarters, State of New York. ? ADJUTANT GENERAL'S OFFICE.

AlBANY, A
General Orders No. I7.

Albany, August 28, I 888.

I. Upon the recommendation of the surgeon-general, persons appointed to medical offices will hereafter be examined, before being commissioned, by special boards selected by the surgeon-general, and hereby appointed:

Returns of appointments of medical officers will be referred by the commanding offcers of brigades to the boards appointed for their respective commands, and all concerned will be governed by the rules prescribed in General Orders No. I4, series I $\$ 87$, from this office, so far as the same are applicable.

2. Appointees to medical offices shall be further examined in the standard branches taught in legally incorpo. rated medical schools; the diagnosis and treatment of injuries and diseases to which troops may be exposed; the means employed for the urgent relief, and for the transportation of sick and wounded, including stretcher drill (see provisional manual of instruction, U. S. A.); camp and personal hygiene; and as to their knowledge of official papers relating to their department.

By order of the commander-in-chief.

Josiah PORTER,

Major-general and Adjutant general.

Now please note the results of the enforcement of this order: The worth of a medical commis- sion in the National Guard is greatly enhanced, and medical men of high attainments now seek positions in the service, serve faithfully, and wait patiently for promotion; the commanding officers respect their value and ability, and, therefore, seek their advice and heed it. The efficient, faithful and conscientious medical officers are now leavening the entire loaf of the medical service, and have become examples for emulation, instead of subjects of pomp or objects of pity, as they were often in the past.

The educational influences of the State Camp, which was established in 1882 , and the introduction of rifle practice throughout the Guard, made the presence of the surgeon, and the importance of his attainments, thoroughly appreciated. Prior to 1887 , the hospital stewards were of the most nondescript character. I recall well the fact that the first hospital steward coming under my charge in the regiment with which I was connected in 1873 was a stable-keeper. He was both faithful and honest, and his assiduity and endurance were phenomenal. His attention to duty was exceeded only by his entire ignorance of the preparation of medicines and their physical properties. For some time prior to I 887 , I had advised that only such as were legally qualified to dispense medicines by the laws of the State relating to pharmacists should be permitted to act as hospital stewards of military organizations. However, my advice in this respect was not heeded until the occurrence of an object lesson which was so emphatic and pointed as to permit of no delay in the issuance, August, r 888, of an order, of which the following is an extract:

"The hospital steward of the regiment in camp, or, if there be none, a suitable person selected by the surgeon-general, will act as post hospital steward under the orders of the postsurgeon and the instructions of the surgeon-general. Such person or hospital steward must have passed an examination before the State Board of Pharmacy, and be licensed as a druggist according to the laws of the State; and regimental and battalion hospital stewards not so examined and licensed will not be recognized by the State, or permitted to act as hospital stewards. Regimental and battalion commanders ordered to camp duty whose hospital stewards do not meet those requirements will at once report the fact to these headquarters."

It may not be amiss now, in view of the im. portance of this order, to narrate the event that inspired its immediate promulgation, especially since this course may serve as a warning, and again aid in the establishment of a reform, the necessity for which at one time came near causing a most distressing accident, if not a fearful calamity in connection with the State Camp of New York. A lady, the wife of an officer of the general staff, visited the State Camp one evening 
to witness the dress parade, and while there was attacked with a severe neuralgic headache, for the relief of which she wished me to prescribe. This I did, going myself to the camp druggist for the remedy, instead of sending an orderly with the prescription, as is the custom. The prescription called for a half grain of codeia and ten grains of bromide of potassium to be taken at once.

While waiting for the compounding of the remedy by the acting hospital steward of the organization then in camp, I leisurely leant against the center pole of the drug-store tent and made a casual survey of the contiguous tents and company streets. A moment after, and almost unconsciously, my attention was directed to the manipulations of this officer compounding the order, and I noticed that he had measured a considerable quantity of a whitish powder, which had not the appearance of bromide of potassium, and was too large an amount, I thought, for the required codeia. I asked, "What is that?" "Codeia," he said. "How much?" I inquired. He replied 'One half a grain, as you ordered.' "It cannot be possible that one half a grain of codeia will make so much bulk," I exclaimed. "Please balance your scales." He did as directed, weighed the powder again and found that there were six and a quarter grains of codeia instead of one half a grain as ordered. You will better appreciate my feelings and excuse this detail of statement, I think, when I tell you that the lady was the wife of the Surgeon-General himself, and that she would have been some distance from camp, no doubt, before the full effects of the drug could have appeared. This lesson is made still more impressive by the fact that the acting hospital steward at that time was an educated physician of some years' experience. And, too, it teaches in no uncertain manner that one unfamiliar with the physical properties of drugs should not be permitted to assume the duties of hospital steward.

Thus the uneducated hospital stewards were disposed of, so far as the service of the State camp was concerned. About one year later the final fatal blow was dealt to the system by the issuance of the following:

"It appearing that there are hospital stewards who are not qualified, according to the laws of the State, to perform the duties required of them, commanding officers are directed to discharge such from the service at once. Hospital stewards should have passed an examination before the State or county boards of pharmacy, and have secured licenses as pharmacists."

There remains but one other feature of the medical service to which I shall call your attention now-the education of a certain number of the rank and file in the simple methods of rendering "prompt aid to the injured." At the present time, in the Guard of the State of New York, the plan of procedure is indicated with sufficient clearness by the following order, which paved the way to its enforcement :

General Headquarters, State of New York. ADJUTANT-GENERAI'S OFFICE. AlbaNy, December 22, 1887 .

General Orders, No. 36.

I. Commanding officers of regiments and battalions, and of batteries and separate companies having a medical officer, will organize ambulance corps in their respective commands as follows:

For a regiment or battalion, the corps shall consist of the medical officers of the command, the hospital steward, and three enlisted men from each company of seventy-five men, and two enlisted men from each company of less than that number.

For a battery or separate company, the corps shall consist of the medical officer and four enlisted men.

'The enlisted men shall be detailed by the commanding officers, upon the recommendation of their senior medical officers, and there may be included in the detail for a regiment or battalion two corporals, and for a battery or separate company one corporal, but no other non-comnissioned officers.

When the exigencies of the occasion require, commanding officers will detail such enlisted men as have already been found proficient, and may also detail musicians for duty with the corps.

Men detailed for ambulance service shall be relieved from such duty on the application of the medical officer having charge of the corps to which they are attached. 2. The corps shall be under the immediate orders, control and instruction of the senior medical officer of the command to which it belongs, but no assignnent or detail for duty with the corps shall relieve an officer or enlisted man from his regular duties, except when on duty with the corps in active service.

3. To prepare the members of the corps for their duties, the medical officer in charge will provide a course of instruction. This course shall commence in the first week in January of each year, and continue during the drill seasons of the year, and shall be open also to such other members of the command of which the corps is a part, as may be approved by its senior medical officer.

The dates, hours and places when and where the instruction will be given, shall be published in orders to the whole command by its commanding officer.

4. The course of instruction given by the medical officers of the command shall include, for the present:

Rudimentary instruction in anatomy and physiology. Rudimentary instruction in the diagnosis of the com. mon accidents and diseased conditions to which National Guardsmen are exposed, and the common meaus for the prevention of the same.

Instruction as to the common means employed for the urgent relief of the sick and the injured, including stretcher drill and matters pertaining to transportation of the sick and injured.

Instruction in individual and camp hygiene.

5. At the close of the course of instruction, the detailed men of the corps shall be examined as to their proficiency, by a board to be appointed for that purpose, as hereinafter provided.

The senior medical officer of each regiment, battalion, battery and separate company, shall keep a record of the name, proficiency and general standing of each member of the ambulance corps under his charge, from the time of the first attendance of the member to the termination of his course of instruction, and also the result of his examination.

6. Commanding officers of brigades will, with the approval of the Surgeon-General, appoint for their respective commands boards of examination, which shall consist of not less than three medical officers, whose 
duty it shall be to examine and report to the brigade commander as to the proficiency of the detailed men who have attended the prescribed course of instruction. These men will be ordered before-the examining board on the application of the commanding officers of the regiment, battalion, battery or separate company to which they belong.

7. Enlisted men of ambulance corps, when actually on duty as such, are authorized to wear, in addition to iusignia of military grade, around the left arm above the elbow, an arm badge (brassard) "of white cloth, I6 inches long and 3 wide, with a cross of red cloth 2 inches high and 2 inches wide in the centre."

8. An enlisted man who has passed the prescribed examination satisfactorily, and has the approval of the commanding officer of the brigade to which lie belongs, will be permitted to wear at all times a badge, of a pattera to be prescribed in further orders, distinctive of the ambulance corps of this State, as an indication of a special fitness to aid the sick and injured under urgent circumstances.

9. Details for instruction in the duties of an ambulance corps will be made annually, at such time as will permit the course of instruction of each succeeding class to begin promptly in the first week in January.

Io. There shall be allowed and issued by the Chief of Ordnance, as Acting Quartermaster-Geveral, State Arsenal, corner Thirty-fifth St. and Seventh Ave., New York City, upon requisition made direct to him by the respective commanding officers, stretchers of a pattern approved by the Surgeon-eneral, at the rate of two for each regiment and battalion, and one for each battery or separate company having a nedical officer.

By order of the Commander in Chief.

JOSIAH PORTER,

Major-General and Adjutant-General.

You will observe that the expression "ambulance corps" is employed in this order, and you will quickest comprehend the contemplated scope of the proposition embodied in the order, I think, if its aims be distinctly isolated at once.

I. The annual education of a definite number of men, many of whom would be declared competent by a board of examiners to render prompt aid to the injured comrade in times of strife, and to the comrade or citizen in the event of physical misfortune in times of peace. These to constitute the ambulance corps of the season.

2. The keeping of a yearly record of the proficiency of each of these men, with the view of the selection of those who are most serviceable when a serious occasion demands. This corps to be the ambulance corps of the occasion.

Already numerous instances have been brought to the attention of the State military authorities of the aid and comfort rendered by these men to the afflicted citizen in case of physical misfortune. And on all occasions in the service of the guard they have given wise advice and commendable injunctions to their comrades, and have promptly and efficiently spanned the important interval between the immediate demands for their own $\mathrm{s}$ fforts and the arrival of a medical officer. It is proper to add in this connection that there is often much opposition on the part of commandants to making the details required by the order, so much in fact that the organization of a permanent corps instead is being given a serious consideration. It might appear unjust on my part were I not impelled to add that this opposition is not a general one by any means, but one that is limited more especially to the smallest of the company and regimental organizations. However, in all of those commands in which unity of purpose, esprit de corps and personal pride of organization are the predominating features, the opportunity to acquire the knowledge is hailed with delight and eagerly accepted. I will now venture the statement that the interest and appreciation exhibited by military commands in measures best intended to increase and extend their importance and usefulness, and the earnestness of their coöperation in them, is in direct proportion to their prosperity, and to the confidence and esteem in which they are held by both the military and civil authorities. The badge mentioned in section 8 of the order is made of coin silver, and bears the red cross and the legend, "Prompt Aid to the Injured" on the face. Thus far it has been permitted to become the property of the winner, and is worn by him on all occasions, civil and military, as evidence of his ability to give prompt aid to the injured of all classes. It is now my opinion that the badge should be the property of the organization, in order that it may not be retained by those who are out of active military service, and for this reason may depreciate its value by its unwarranted use, and by failing to keep pace with the requirements of the service. At all events, some evidence should be retained by the worthy members at all times which will justify the belief that they are competent to perform their duties in this service, and will offer to them the opportunity and right of receiving instruction when sought for, and bear evidence of continued assiduity and competence on their part.

\section{[NEW ORDER.]}

GeNERAT, HeAdQUARTERS, STATE OF NEW YORK, ADJU'TAN'T-GFNERAI'S OFFICE, ArbaNy, September 3, $189 \mathrm{r}$. General Orders No. 23.

I. General Orders No. 36, from these headquarters, dated Dec. 22 , I 887 , providing for the organization of ambulance corps, and for the instruction of men detailed for ambulance service, is hereby revoked, and the following substituted therefor:

2. Commanding officers of regiments and battalious, and of troops, batteries and separate companies baving a medical officer, will organize ambulance corps in their respective commands, but the corps in existence at this date in accordance with general orders No. 36 , of these beadquarters, series 1887 , will be continued under the provisions hereinafter prescribed.

For a regiment or battalion, the corps shall consist of the medical officers of the command, the hospital steward, and as company bearers three enlisted men from each company of seventy-five men, and two enlisted men from each company of less than that number.

For a troop, battery or separate company, the corps shall consist of the medical officer and as company bearers four enlisted men.

The details for company bearers will be made by the 
commanding officer of the organization of which the corps is a part, upon the recommendation of his senior medical officer. The men selected must possess the ability and intelligence necessary for the requirements of this service. There may be included in the detail for a regi ment or battalion not more than two corporais, and for a troop, battery or separate company not more than one corporal; but if a member of the corps should be promoted to a non-commissioned office he shall be allowed, if he so desire, to complete the course of instruction, and after he has passed the examination prescribed below, the senior medical officer may select him as one of the non-commissioned officers authorized.

Men detailed to an ambulance corps shall be relieved from such duty on the application of the medical officer having charge of the corps to which they are attached. Whenever actual relief for sick or injured is required, the commanding officer will detail such enlisted men as have attended the course of instruction, and may also detail musicians for such service.

3. When on ambulance duty, or under instruction, the corps shall be ander the immediate orders and control of the senior medical officer of the command to which it belongs, but no assignment or detail for duty with the corps shall relieve an officer or enlisted man from his regular duties, except when actually on duty with the corps in active service.

4. To prepare the members of the corps for their duties, the medical officer in charge will provide a course of instruction. This course shall commence in the first month of the drill season of each year and be held at least once in two weeks during such season. It shall be open also to such other members of the command of which the corps is a part as may be approved by its senior medical officer.

The dates, hours and places when and where the in. struction $w^{\prime}$ ill be given shall be published in orders to the whole command by its commanding officer.

5. The course of instruction, given by the medical officers of the command, shall include, for the present:

Rudimentary instruction in anatomy and physiology.

Rudimentary instruction in the diagnosis of the nature of accidents and disease manifestations to which national guardsmen are subject, and the common means for the prevention and treatment of the same.

Instruction as to the common means employed for the urgent relief of the sick and the injured, including stretcher-drill and matters pertaining to transportation of the sick and injured.

Instruction in individual and camp hygiene.

6. At the close of the course of instruction, the detailed men of the corps shall be examined as to their proficiency by a board to be appointed for that purpose as hereinafter provided.

The senior medical officer of each regiment, battalion, troop, battery and separate company shall keep a record of the name, proficiency and general standing of each member of the ambulance corps under his charge, from the time of the first attendance of the member to the termination of his course of instruction, also the result of his examinations, and the number of the badge if one is awarded to him.

7. Commanding officers of the brigades will, with the approval of the Surgeon-General, appoint for their respective commands boards of examination which shall consist of not less than three medical officers, whose duty it shall be to examine and report to the brigade commander as to the proficiency of the detailed men who have atteuded the prescribed course of instruction. The presiding officer of each board shall notify the commanding officers of the organizations of his brigade of the dates on which the board will be in session, and when they will examine the detailed men of the respective corps. These men shall then be ordered before the examining board by the commanding officer of the regiment, battalion, troop, battery or separate company to which they belong, and those who pass the prescribed examination shall form the ambulance corps of their respective organizations, and remain members of the same subject to the approval of the medical officer in charge, and subject also to an annual examination by the board mentioned.

8. Enlisted men of ambulance corps, when actually on duty as such, are authorized to wear around the left arm above the elbow (uon-commissioned officers as far above the chevron as practicable) an arm badge ("brassard") of white cloth, sixteen inches long and three wide, with a cross of red cloth two inches high and two inches wide in centre.

9. An enlisted man who has been detailed to an ambulance corps, and who has passed the prescribed examination satisfactorily, and has the approval of the commanding officer of the brigade to which he belongs, will be permitted to wear, with the consent of the commanding officer mentioned below, while a member of the corps, on dress and undress uniforms, and when in citizen's dress, the badge of the ambulance corps of this State, of the pattern heretofore issued, as an indication of special fitness to aid the sick and injured under urgent circumstances; this badge shall be turned into the regimental, battalion, troop, battery or company commander of the soldier, when the latter ceases to be a member of the organization, and such commander shall be responsible to the State for the same, and shall bave the power for good reasons to refuse permission to wear or decline to issue the same to any one.

ro. Details to fill vacancies in the ambulance corps will be made upon the recommendation of the medical officers, if possible from those who have attended the course of instruction, and who appear upon competitive examination to be best qualified for the duties.

II. When a nember of the ambulance corps ceases to be a member of the regiment, battalion, troop, battery or separate company, he shall receive, from the SurgeonGeneral of the State, upon the recommendation of the medical officer and the commanding officer, as evidence of his special qualifications and ability to perform the duties of the corps, a certificate to that effect, which certificate will entitle the owner to receive instruction in the duties of the corps at regular intervals, aud to be examined in the same, and to have the result of the examination indorsed on the certificate.

I2. There shall be allowed and issued by the Chief of Ordnance, as Acting Quartermaster-General, in cases where such issue has not already been made, upon requisition made direct to him by commanding officers, stretchers of a pattern approved by the Surgeon General, at the rate of two for each regiment and battalion, and one for each troop, battery or separate company having a medical officer.

13. The Brigade Commanders and the Surgeon-General, and under him the brigade surgeons are charged with the prompt execution of this order, in their own sphere, and the latter and the Surgeon-General, in matters of instruction and advice, will communicate directly with the medical officers in charge of corps.

By order of the Commander-in-Chief.

JOSIAH PORTER, Adjutant-General.

Official. Ass't Adj't General.

I will not detain you longer, as, it seems to me, sufficient has been said already to provide a substantial foundation for wise action in the future. Permit me, in conclusion, to offer the following recommendations for your consideration :

I. The requirement that all medical applicants should be caused, before entering the Guard in 
the capacity of medical officers of commands, to pass an examination that shall be a rigid test of their ability to meet the demands of the position which they seek.

2. The requirement that all hospital stewards shall be fully qualified by law or by practice to dispense medicines intelligently and correctly.

3. The requirement that a suitable number of intelligent members of a command be instructed, examined, and be passed when proficient in the details essential to the rendering of "prompt aid to the injured," and of bestowing wise care on the sick.

4. The requirement that such worthy members be permitted to have in their possession a suitable badge, or other testimonial, at all times, as evidence of their ability.

In conclusion, permit me to express the belief that the formation of a scientific body from the medical officers of the Guard should be made secondary to the development of an efficient system of practical medical service in the Guard. And even then it seems to me that it can but be based upon an uncertain and fickle tenure, so long as no wise and judicious control can be exercised as to the personnel of its membership. It ought not to be overlooked that the commission bestowed by the State is the certificate of membership, not the requirements that few or many of the members may see fit to demand. Not to recognize a commission issued to its representative by a State or Territory is subversive of discipline, and can but lead, in my judgment, to dense demoralization, unmannerly bickering, and the breeding of life-long animosities, all of which are destructive of harmony and efficiency, and contrary to the laws and traditions of the service to which we belong.

\section{BOOK REVIEWS.}

A Treatise on the Diseases of Infancy and ChildHoon. By J. LEwIs SMrTh, M.D. Clinical Professor of Diseases of Children, Bellevue Hospital Medical College; Physician to Charity Hospital; Physician to the New York Foundling Asylum; Physician to the New York Infant Asylum; Consulting Physician to the Department of Children's Diseases, Bureau of Relief for the Out-door Poor, Bellevue; Consulting Physician to the Nursery and Child's Hospital, County Branch; Consulting Physician to the Infants' Hospital, Randall's Island. Seventh Edition, thoroughly revised, with Fifty-one Illustrations. Philadelphia: Lea Brothers \& Co. I89o. Chicago: A. C. McClurg Co., II7-I2I Wabash Ave. Price, cloth, $\$ 4.50$; sheep, $\$ 5.50$.

Six efitions of this work have been presented to the medical profession. The seventh being in demand, the opportunity was given for a thorough revision of the entire book, of which Professor Smith has so fully aviled himself, that not only has the volume been increased to nearly double its former size, but in its revision he has been able to incorporate recent investigations and discoveries pertaining to the bacterial origin of many of the diseases of infancy and childhood-without which it would not meet the present requirements of the profession, Very properly, in the first hundred pages, the subjects of food, bathing, clothing, sleep and exercise are dealt with, and in a manner highly satisfactory. Diseases of the newborn and constitutional diseases are very fully described, and in addition to the author's views as to their pathology and treatment, citations are freely made from a large number of our most accredited authors bearing upon the affections successively considered. A special feature of the work is the prominence given to diseases of the cerebro-spinal system, while those of the digestive apparatus and of the circulatory system are amply delineated, and methods of treatment are very fully considered.

The careful consideration given to "new remedies" will be helpful to those not yet faniliarized with their actions and the conditions in which their uses are indicated.

The present revision gives a greatly added value to the work, and, as in the past, it will continue to be one of our most reliable and helpful treatises on tiseases of in. fancy and childhood.

Painful, Menstruation. By Francis Henty ChampNEYS, M.D., M.A., Oxon., etc. Published by H. K. Lewis, London.

This little brochure of nearly roo pages consists in substance of the Harveian lectures for 1890 . The subject is not only an important one but in the author's handis has been developed into one of great interest. Unlike the majority of English authors Dr. Champneys has a succinct and practical style which is a sine qua non in medical monograpbs. The subject of membraneous dysmenorrhoea received considerable atteution, several large tables being appended which contain the complete bibliography of this interesting subject. The busy practitioner will find the work a valuable one.

Parkes Manual of Practical Hygiene (eighth edition exlited by J. LANE NOTTER, M.A., M.D. Published by P. Blakiston Son \& Co., Philadelphia.

This is an old friend in a new garb. The work has been thoroughly revised and brought up to date. The standard character of the work is so universally acknowledged that it is hardly necessary to state that it is among the best works upon practical hygiene that have ever been published.

TRANSACTIONS OF THE 12 TH ANNUAL MEETING OF THE AMERICAN LARYNGOLOGICAI ASSOCIATION. Published by D. APPLETON \& CO., N. Y.

This little work is a digest of the proceedings of the I th annual assembly of the American Laryngological Association held in Baltimore, Md., May 29-3I, I89o, inclusive, and is certainly suggestive of the enterprise and character of the members of this society-and is well worthy emulation by other medical organizations. Its pages are replete with many well written articles on laryngological and rhinological topics, together with discussions thereon. Its initial article is in substance a very practical address by Dr. Jno. N. McKenzie, president of the society, who gives in outline the objects of the association and shows the practical and great good that has followed the organization. Altogether it may be said that the work can be perused with advantage by both the general practitioner and specialist. 